\title{
ANZAED practice and training standards for dietitians providing eating disorder treatment
}

\author{
Gabriella Heruc ${ }^{1,2,3^{*}}$ (D), Susan Hart ${ }^{4,5}$, Garalynne Stiles ${ }^{6}$, Kate Fleming ${ }^{7}$, Anjanette Casey ${ }^{8}$, Fiona Sutherland ${ }^{1,9}$, \\ Shane Jeffrey ${ }^{1,10,11}$, Michelle Roberton ${ }^{12}$ and Kim Hurst ${ }^{1,13,14}$
}

\begin{abstract}
Introduction: Dietitians involved in eating disorder treatment are viewed as important members of the multidisciplinary team. However, the skills and knowledge that they require are not well characterised. Therefore, as part of a broader project to identify the key principles and clinical practice and training standards for mental health professionals and dietitians providing eating disorder treatment, the Australia \& New Zealand Academy for Eating Disorders (ANZAED) sought to identify the key practice and training standards specific to dietitians. An expert working group of dietitians was convened to draft the initial dietetic standards. After expert review, feedback on the revised standards was then provided by 100 health professionals working within the eating disorder sector. This was collated into a revised version made available online for public consultation, with input received from treatment professionals, professional bodies and consumer/carer organisations.

Recommendations: Dietitians providing treatment to individuals with an eating disorder should follow ANZAED's general principles and clinical practice standards for mental health professionals and dietitians. In addition, they should also be competent in the present eating disorder-specific standards based around the core dietetic skills of screening, professional responsibility, assessment, nutrition diagnosis, intervention, monitoring and evaluation.

Conclusions: These standards provide guidance on the expectations of dietetic management to ensure the safe and effective treatment of individuals with an eating disorder. Implications for professional development content and training providers are discussed, as well as the importance of clinical supervision to support professional self-care and evidenceinformed and safe practice for individuals with an eating disorder.
\end{abstract}

Keywords: Dietetic, Dietitian, Eating disorder, Nutrition, Practice standards, Training, Treatment

\section{Plain English summary}

Dietitians play an important role in eating disorder treatment, however the skills and knowledge they require to provide safe and effective treatment is not well defined. This paper aimed to describe the clinical practice and training standards for dietitians providing eating disorder treatment. The Australia \& New Zealand Academy

\footnotetext{
* Correspondence: g.heruc@westernsydney.edu.au

${ }^{1}$ Executive Committee, Australia \& New Zealand Academy for Eating Disorders, Sydney, Australia

${ }^{2}$ School of Medicine, Western Sydney University, Campbelltown, Australia

Full list of author information is available at the end of the article
}

for Eating Disorders undertook extensive consultation to establish agreement around what constitutes best dietetic practice in the treatment of individuals with an eating disorder. The resulting standards were based around the core dietetic skills of screening, professional responsibility, assessment, nutrition diagnosis, intervention, monitoring and evaluation, and also outlined the expectations for training and supervision.

(c) The Author(s). 2020 Open Access This article is licensed under a Creative Commons Attribution 4.0 International License, which permits use, sharing, adaptation, distribution and reproduction in any medium or format, as long as you give appropriate credit to the original author(s) and the source, provide a link to the Creative Commons licence, and indicate if changes were made. The images or other third party material in this article are included in the article's Creative Commons licence, unless indicated otherwise in a credit line to the material. If material is not included in the article's Creative Commons licence and your intended use is not permitted by statutory regulation or exceeds the permitted use, you will need to obtain permission directly from the copyright holder. To view a copy of this licence, visit http://creativecommons.org/licenses/by/4.0/ The Creative Commons Public Domain Dedication waiver (http://creativecommons.org/publicdomain/zero/1.0/) applies to the data made available in this article, unless otherwise stated in a credit line to the data. 


\section{Introduction}

The role of the dietitian in providing eating disorder treatment as part of the multidisciplinary team has been widely recognised [1-3]. Dietitians play a pivotal role in helping individuals with eating disorders and their families understand the interaction between food, nutrition and wellbeing, as well as supporting eating behaviours that align with their treatment and recovery goals. Eating disorders have high morbidity and mortality rates [4], and failure to provide early intervention is associated with a longer duration and severity of illness, serious physical health consequences and a higher risk of mortality including risk of suicide [5]. However, morbidity and mortality in individuals with an eating disorder can be improved with effective treatment [5]. Nutritional care contributes to improving quality of life and morbidity and mortality rates in general dietetics [6], but the dietitian's role in eating disorder treatment is less clear and the specifics of dietetic practice are not well defined [7].

Although current clinical practice guidelines recommend dietetic assessment, education and intervention as part of the multidisciplinary treatment of eating disorders [1-3], there is a lack of detailed guidance for dietitians regarding what outpatient dietetic treatment for eating disorders should encompass [8]. Moreover, there is an absence of internationally accepted dietetic models of care within the eating disorders field, which may increase the likelihood of inconsistent interventions [9] and limit clarity regarding the role of the dietitian, both within the dietetic profession [10] and more broadly for other health professionals [11]. Dietetic scope of practice in the treatment of eating disorders is diverse, but at a minimum should include a tailored nutrition care process that: corrects nutritional deficiencies and promotes optimal nutrition status; addresses the role of eating and adequate nutrition in physical and mental well-being; and provides nutrition education to challenge inaccurate beliefs about food $[2,7,12,13]$. Having clearly defined practice standards for dietitians will ensure effective, safe and timely care for individuals with an eating disorder in addition to consistent treatment approaches.

The role of dietitians in eating disorder treatment also appears to be affected by the adequacy of dietitian training with dietitians feeling that dietetic training is inadequate preparation for practice in eating disorders [14, 15]. Communication and nutrition counselling in particular are often insufficiently addressed at university, resulting in a gap in skillset for most dietitians [16, 17]. Thus, dietitians providing eating disorder treatment often seek further clinical experience, post graduate training and professional supervision [14]. To support ethical and effective dietetic care in eating disorder treatment, clarification is required on the knowledge and skills that training programs need to address.
The current clinical practice and training standards aim to describe the role of the dietitian in eating disorder treatment and provide a roadmap for dietitians to provide effective and safe care. This document builds on the Australia \& New Zealand Academy for Eating Disorders (ANZAED) general principles and practice and trainings standards for all clinicians providing eating disorder treatment concurrently published in the Journal of Eating Disorders [18]. Based around the core dietetic skills of screening, professional responsibility, assessment, nutrition diagnosis, intervention, monitoring and evaluation, it details the knowledge and skills that dietitians require to competently manage and treat individuals with an eating disorder. It also describes the expectations and content required to be addressed in training programs that provide education on the therapeutic knowledge and skills outlined in these practice standards. Consistent and standardised dietetic practice may not only enhance the legitimacy and credibility of dietitians as part of the multidisciplinary team, but may also lead to improvements in clinical care for individuals with eating disorders.

\section{Methods of dietetic-specific practice and training standards development}

ANZAED established an expert working group of eight dietitians with representatives from Australia and New Zealand, each with between 12 and 30 years of clinical experience in eating disorder treatment. This was part of a broader project to develop general clinical practice and training standards [18], as well as standards specific to mental health professionals [19] and dietitians providing eating disorder treatment.

The working group initially developed draft dieteticspecific standards based on published evidence and clinical experience, which were reviewed and refined by ANZAED's Executive Committee and expert advisors. As part of a combined clinical practice and training standards document, the next draft version was then presented for public face-to-face consultation without anonymity at the ANZAED 2019 Conference in Adelaide, with feedback received and incorporated from eating disorder professionals $(n=100)$. Following this, online consultation from the broader public was sought, with feedback received from international expert advisors, professional bodies (various disciplines) and consumer and carer groups with comments reviewed and integrated by the working groups. The final version was also reviewed by the National Eating Disorder Collaboration Steering Committee and again by ANZAED's Executive Committee. Consensus was reached through discussion by the authors and there was no identified conflict of interest. The resulting dietetic-specific clinical practice standards are detailed below and in Table 1 . 
Table 1 Dietetic-specific clinical practice and training standards. The table below describes in detail the dietetic-specific practice and training standards that were summarised in the Recommendations section. It outlines the specific practice points recommended that dietitians be taught, understand and utilise to ensure safe and effective eating disorder treatment

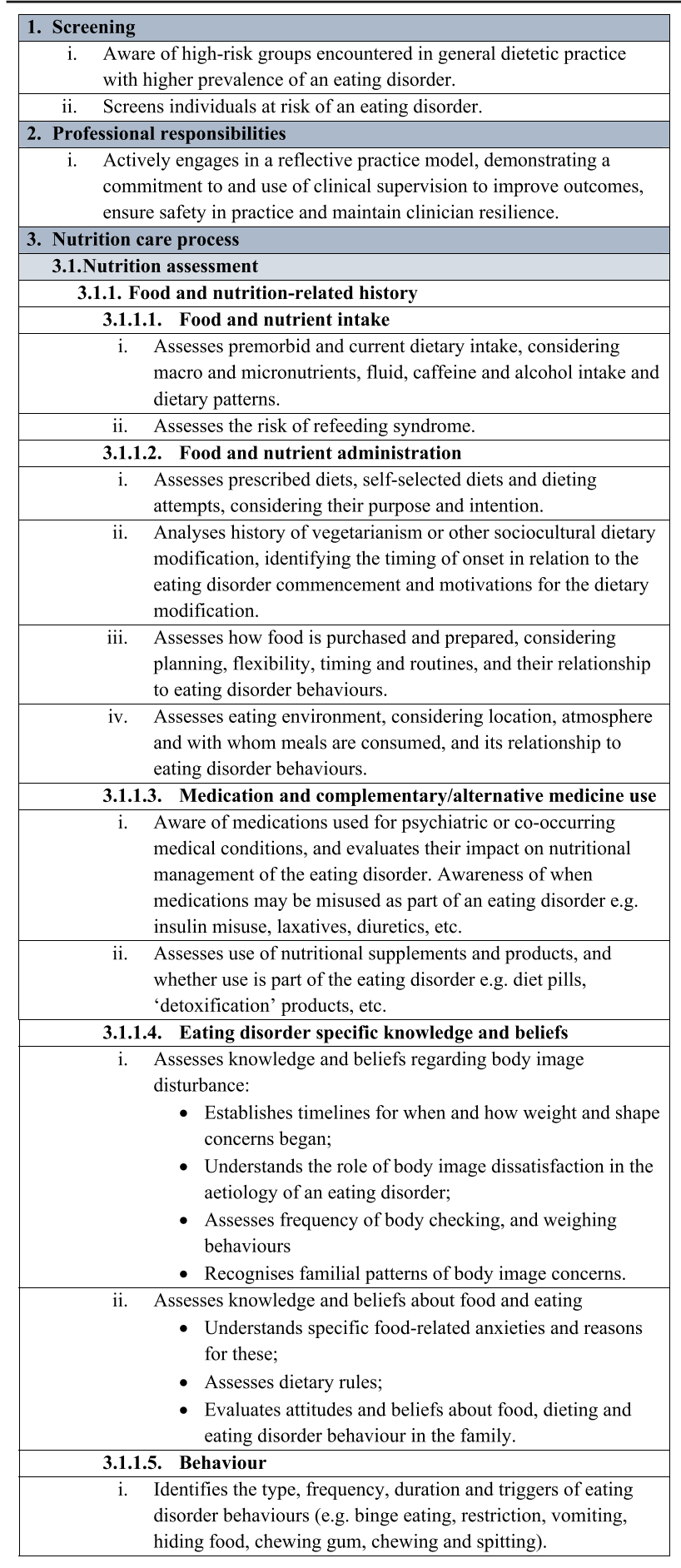

Table 1 (Continued)

\begin{tabular}{|c|}
\hline $\begin{array}{l}\text { 3.1.1.6. Factors affecting access to food and food/nutrition- } \\
\text { related supplies }\end{array}$ \\
\hline $\begin{array}{l}\text { i. Considers food and fluid availability, accessibility and safety } \\
\text { and shopping facilities and its effects on eating disorder } \\
\text { behaviours. }\end{array}$ \\
\hline $\begin{array}{l}\text { ii. Identifies current participation in programs providing } \\
\text { food/nutrition, such as home enteral nutrition programs, day } \\
\text { programs and residential programs. }\end{array}$ \\
\hline 3.1.1.7. Physical activity and function \\
\hline $\begin{array}{l}\text { i. Analyses current and premorbid physical activity levels, } \\
\text { including frequency, duration, type, motivation and compulsion. }\end{array}$ \\
\hline $\begin{array}{l}\text { ii. Recognises any sport-specific nutrition needs for competitive } \\
\text { athletes. }\end{array}$ \\
\hline iii. Recognises familial patterns of exercise and physical activity. \\
\hline 3.1.1.8. Nutrition-related person-centred measures \\
\hline $\begin{array}{l}\text { i. Understands the individual's perception of the nutrition } \\
\text { intervention and the impact on their quality of life. }\end{array}$ \\
\hline $\begin{array}{l}\text { ii. Identifies the individual's aims of nutrition intervention in the } \\
\text { context of eating disorder treatment. }\end{array}$ \\
\hline 3.1.2. Anthropometric measurements \\
\hline $\begin{array}{l}\text { i. Determines weight history, including highest and lowest weights } \\
\text { reached, as well as weight fluctuations. }\end{array}$ \\
\hline $\begin{array}{l}\text { ii. Evaluates eating disorder effects on growth (e.g. in children, } \\
\text { adolescents and pregnant women). }\end{array}$ \\
\hline Enquires about the individual's desired weight. \\
\hline Assesses body weight and shape patterns in the family. \\
\hline 3.1.3. Biochemical data, medical tests and procedures \\
\hline $\begin{array}{l}\text { i. Understands and reviews biochemistry results and other physical } \\
\text { assessment measures (e.g. blood pressure, heart rate, etc.) in relation } \\
\text { to eating disorder impacts on nutritional status. }\end{array}$ \\
\hline $\begin{array}{l}\text { ii. Understands the impact of eating disorder behaviours on diagnostic } \\
\text { test results (e.g. bone densitometry, electrocardiogram). }\end{array}$ \\
\hline $\begin{array}{l}\text { iii. Communicates with and escalates any concerns regarding nutritional } \\
\text { status, biochemistry and physical assessment measures to the } \\
\text { individuals' medical practitioner. }\end{array}$ \\
\hline 3.1.4. Nutrition-focused physical findings \\
\hline $\begin{array}{l}\text { i. Assesses actual or potential physical and psychiatric complications of } \\
\text { eating disorder behaviours, including consequences of under-nutrition, } \\
\text { starvation and compensatory behaviours. }\end{array}$ \\
\hline $\begin{array}{l}\text { ii. Obtains history of gastrointestinal signs and symptoms in the context } \\
\text { of the eating disorder and comorbidities. }\end{array}$ \\
\hline $\begin{array}{l}\text { iii. Assesses past and current menstrual function in anyone who identifies } \\
\text { as female or is expected to menstruate (including transgender males } \\
\text { and non-binary individuals who were born as female). }\end{array}$ \\
\hline $\begin{array}{l}\text { iv. Assesses appetite awareness including hunger, fullness and satiety } \\
\text { cues. }\end{array}$ \\
\hline 3.1.5. Individual's history \\
\hline 3.1.5.1. Personal history and experiences \\
\hline $\begin{array}{l}\text { i. Considers relationship with body and food prior to the } \\
\text { development of the eating disorder. }\end{array}$ \\
\hline $\begin{array}{l}\text { ii. Identifies current and past life stressors that may have } \\
\text { contributed to the development of body image concerns, } \\
\text { relationship with food and eating disorder behaviours. }\end{array}$ \\
\hline $\begin{array}{l}\text { iii. Recognises when and how the eating disorder started and } \\
\text { progressed. }\end{array}$ \\
\hline $\begin{array}{l}\text { iv. Seeks to understand lived experience with any weight-based } \\
\text { stigmatisation, including within the health care system. }\end{array}$ \\
\hline $\begin{array}{l}\text { v. Seeks to understand previous experiences with nutrition } \\
\text { professionals. }\end{array}$ \\
\hline
\end{tabular}


Table 1 (Continued)

\begin{tabular}{|c|c|}
\hline \multicolumn{2}{|l|}{3.1} \\
\hline i. & $\begin{array}{l}\text { Recognises psychiatric comorbidities (including self-harm and } \\
\text { suicidal risk). }\end{array}$ \\
\hline & $\begin{array}{l}\text { Determines relevant medical comorbidities and their impact of } \\
\text { managing the eating disorder (e.g. diabetes, allergies, } \\
\text { gastrointestinal disorders, etc.). }\end{array}$ \\
\hline \multicolumn{2}{|c|}{ 3.1.5.3. Social history } \\
\hline \multicolumn{2}{|c|}{ i. Understands the as } \\
\hline & $\begin{array}{l}\text { eating disorder, including the impact of their profession, } \\
\text { education, living situation and relationships. }\end{array}$ \\
\hline \multicolumn{2}{|c|}{ 3.1.6. Comparative standards } \\
\hline \multicolumn{2}{|r|}{$\begin{array}{l}\text { i. Estimates overall energy and fluid needs and individual } \\
\text { macronutrient requirements. }\end{array}$} \\
\hline \multicolumn{2}{|r|}{$\begin{array}{l}\text { ii. Estimates body weight range if applicable, considering age and } \\
\text { growth, life history, genetics and relevant medical conditions. }\end{array}$} \\
\hline \multicolumn{2}{|c|}{ 3.2. Nutrition diagnosis } \\
\hline \multicolumn{2}{|c|}{ 3.2.1. Intake } \\
\hline & $\begin{array}{l}\text { Assesses and identifies nutrition intake problems pertaining to } \\
\text { the eating disorder (e.g. intentional over- or under-hydration, } \\
\text { avoidance of particular nutrients, etc.) }\end{array}$ \\
\hline & $\begin{array}{l}\text { Develops an 'intake' nutrition diagnosis statement that } \\
\text { adequately informs multidisciplinary treatment team members } \\
\text { whose interventions influence the nutrition care of the } \\
\text { individual, on 'intake' nutrition problems to prioritise as part of } \\
\text { eating disorder treatment. }\end{array}$ \\
\hline \multicolumn{2}{|c|}{ 3.2.2. Clinical } \\
\hline & $\begin{array}{l}\text { Identifies aetiology of 'intake' nutrition problems as eating } \\
\text { disorder behaviours when relevant. }\end{array}$ \\
\hline & $\begin{array}{l}\text { Identifies aetiology of clinical nutrition problems (e.g. altered } \\
\text { gastrointestinal function, underweight) as medical } \\
\text { complications of eating disorder behaviour when relevant. }\end{array}$ \\
\hline \multicolumn{2}{|c|}{ 3.2.3. Behavioural-environmental } \\
\hline & $\begin{array}{l}\text { Differentiates between the nutrition problems of disordered } \\
\text { eating patterns related to body image disturbance (typically } \\
\text { present in anorexia nervosa, bulimia nervosa and binge-eating } \\
\text { disorder) and limited food acceptance (typically present in } \\
\text { avoidant restrictive food intake disorder). }\end{array}$ \\
\hline & $\begin{array}{l}\text { Recognises known risk factors (e.g. history of dieting, family } \\
\text { history of an eating disorder) and eating disorder pathology (e.g } \\
\text { fear of weight gain) identified in the assessment as aetiology of } \\
\text { the nutrition problem disordered eating pattern when identified. }\end{array}$ \\
\hline & $\begin{array}{l}\text { Identifies signs and symptoms which can inform whether an } \\
\text { individual's presentation may meet DSM- } 5 \text { diagnostic criteria } \\
\text { for an eating disorder e.g. frequency of binge eating or purging. }\end{array}$ \\
\hline \multicolumn{2}{|c|}{ 3.3.Nutrition intervention } \\
\hline \multicolumn{2}{|c|}{ 3.3.1. Nutrition intervention planning } \\
\hline \multicolumn{2}{|c|}{ i. Plans the nutrition intervention with conside } \\
\hline \multicolumn{2}{|c|}{$\begin{array}{l}\text { ii. Considers the stage in the eating disorder treatment process and level } \\
\text { of carer support recommended within treatments. }\end{array}$} \\
\hline \multicolumn{2}{|c|}{ iii. Encourages inclusion of a wide variety of foods from all food groups, } \\
\hline \multicolumn{2}{|c|}{$\begin{array}{l}\text { iv. Emphasises increased flexibility of food choice, eating out socially } \\
\text { and eating for enjoyment rather than to influence weight or shape. }\end{array}$} \\
\hline \multicolumn{2}{|c|}{$\begin{array}{l}\text { v. Prescribes the appropriate energy level (or intake) as part of the } \\
\text { nutrition plan, considering strengths and risks of different nutrition } \\
\text { support models such as sample meal plans, dietary portions, and plate } \\
\text { models. }\end{array}$} \\
\hline
\end{tabular}

Table 1 (Continued)

\begin{tabular}{|c|c|}
\hline \multicolumn{2}{|r|}{ 3.3.2. Nutrition intervention implementation } \\
\hline & 3.3.2.1. Food and nutrient delivery \\
\hline & $\begin{array}{l}\text { Prescribes energy and nutritional support via oral nutrition with three } \\
\text { nutritionally adequate meals and } 2-3 \text { snacks, with consideration of } \\
\text { high energy supplements and recommendations for enteral feeding } \\
\text { when required. This includes: } \\
\text { - Energy and macronutrient requirements and how these might be } \\
\text { achieved e.g. adequate carbohydrate intake to manage } \\
\text { hypoglycaemia during refeeding in anorexia nervosa; } \\
\text { - All micronutrient requirements especially iron, calcium and } \\
\text { vitamin D and the need for micronutrient supplementation if } \\
\text { required; } \\
\text { - Fluid requirements recognising that many individuals with } \\
\text { eating disorders may drink much less or more than they need. }\end{array}$ \\
\hline & $\begin{array}{l}\text { Determines the appropriate rate of nutrient delivery considering the } \\
\text { risk of refeeding syndrome. }\end{array}$ \\
\hline & $\begin{array}{l}\text { If risk factors for refeeding syndrome are present, recommends risk } \\
\text { mitigation strategies such as phosphate and thiamine supplementation. }\end{array}$ \\
\hline & $\begin{array}{l}\text { Provides education on common side effects of resuming adequate } \\
\text { eating such as on gastrointestinal discomfort, constipation and } \\
\text { bloating. }\end{array}$ \\
\hline & $\begin{array}{l}\text { Refers to evidence-based information to provide advice on exercise } \\
\text { during treatment based on medical risk and weight progress, in } \\
\text { conjunction with other members of the multidisciplinary team. }\end{array}$ \\
\hline & 3.3.2.2. Nutrition education \\
\hline & $\begin{array}{l}\text { Provides nutrition education to individuals across all stages of eating } \\
\text { disorder presentation and treatment settings. }\end{array}$ \\
\hline & $\begin{array}{l}\text { Includes education topics such as gut function, appetite regulation, } \\
\text { weight and body changes, the role of nutrients, achieving an adequate } \\
\text { energy intake, social eating and incorporating exercises. }\end{array}$ \\
\hline & $\begin{array}{l}\text { Tailors education to the stage and type of eating disorder treatment } \\
\text { and developmental stage of the individual (e.g. growth needs of } \\
\text { adolescents). }\end{array}$ \\
\hline & $\begin{array}{l}\text { Provides nutrition and meal support education to those providing } \\
\text { meals appropriate for the treatment context, including family, carers } \\
\text { and treatment facility food service and meal support staff. }\end{array}$ \\
\hline & 3.3.2.3. Nutrition counselling \\
\hline & $\begin{array}{l}\text { Adapts nutrition counselling to level of motivation, developmental } \\
\text { expectations, psychological treatment model and psychiatric co- } \\
\text { morbidities. }\end{array}$ \\
\hline & $\begin{array}{l}\text { Applies specific strategies that may be used in nutrition counselling } \\
\text { such as motivational interviewing, goal setting, and self-monitoring, }\end{array}$ \\
\hline & $\begin{array}{l}\text { Aware of specific strategies that may be used in nutrition counselling } \\
\text { with further adequate training, such as graded exposure, behavioural } \\
\text { experiments, structured problem solving and relapse prevention. }\end{array}$ \\
\hline & $\begin{array}{l}\text { Incorporates concepts of internalised weight bias and weight stigma } \\
\text { and how this influences body image into counselling. }\end{array}$ \\
\hline \multicolumn{2}{|r|}{ 3.3.3. Coordination of nutrition care } \\
\hline & $\begin{array}{l}\text { Collaborates with members of the multidisciplinary team to develop } \\
\text { treatment plans with mutually agreed goals and clearly defined roles. } \\
\text { This may involve recommendations for higher levels of care. }\end{array}$ \\
\hline & $\begin{array}{l}\text { Seeks regular consultation and supervision specific to eating disorder } \\
\text { treatment with more senior colleagues. }\end{array}$ \\
\hline & $\begin{array}{l}\text { Understands the principles of privacy, confidentiality, consent and } \\
\text { duty of care. }\end{array}$ \\
\hline & $\begin{array}{l}\text { Liaises with food delivery services and communicates the nutrition } \\
\text { plan for food delivery. }\end{array}$ \\
\hline \multicolumn{2}{|c|}{ 3.4.Monitoring and evaluation } \\
\hline \multicolumn{2}{|r|}{$\begin{array}{l}\text { i. Monitors and evaluates qualitative and quantitative key nutrition } \\
\text { indicators relevant to eating disorder pathology as identified in the } \\
\text { assessment. }\end{array}$} \\
\hline ii. $\begin{array}{l}\mathrm{C} \\
\mathrm{m}\end{array}$ & $\begin{array}{l}\text { ommunicates requirements for monitoring and evaluation within the } \\
\text { ultidisciplinary team if not undertaken directly by the dietitian. }\end{array}$ \\
\hline
\end{tabular}




\section{Recommendations}

\section{Dietetic-specific clinical practice standards}

It is recommended that dietitians providing treatment to individuals with an eating disorder follow the broad principles and practice standards outlined in The Australia \& New Zealand Academy for Eating Disorders treatment principles and general clinical practice and training standards for mental health professionals and dietitians [18]. In addition, to provide safe and effective treatment, it is recommended that dietitians treating individuals with an eating disorder are also competent in the dietetic-specific clinical practice standards summarised below and detailed in Table 1. General dietetic skills are assumed, in line with dietetic competencies set out by relevant dietetic registering bodies, and are not mentioned here.

\section{Screening}

The prevalence of eating disorder presentations in general dietetic practice remains unknown. However, all dietitians have an important role in early identification and the screening of high-risk individuals using evidence-based tools, such as the SCOFF [20], and BEDS-7 [21]. For many individuals with an eating disorder there are no, or few, obvious signs of ill-health. Without timely and appropriate screening and assessment, an opportunity for detection of symptoms may be missed [22, 23].

Individuals who should be screened for an eating disorder may present to a dietitian to discuss their dietary concerns without specifically seeking treatment or support for an eating disorder. Individuals might belong to groups where there is a higher prevalence of eating disorders, including those: (a) at higher [24] or lower body weights [25]; (b) with recent rapid weight loss or gain [26]; (c) presenting for weight management with concomitant significant concerns about appearance and/or repeated efforts to change body shape (pursuing weight loss, or gain) [27]; (d) following a self-imposed (e.g. gluten-free, food allergy -/intolerance-related, vegan) $[27,28]$ or medically prescribed restrictive diet (e.g. due to type 1 diabetes, coeliac disease [29-31] or low 'FODMAP' diet due to irritable bowel syndrome [32]); (e) post-bariatric surgery [33]; (f) presenting with unspecified gastrointestinal symptoms such as constipation or abdominal pain [34, 35], or with a diagnosis of irritable bowel syndrome [32]; (g) presenting with physical symptoms or electrolyte disturbance that could be attributed to starvation/malnutrition or purging behaviour [36]; (h) being a restrained eater [37], or restricting energy and nutritional intake [38]; (i) having a concurrent mental health concern [22, 39]; and (j) elite athletes who participate in individual sports or that require meeting a weight criterion (e.g. lightweight rowers, jockeys, martial arts practitioners, boxers, dancers, gymnasts) [40].

\section{Professional responsibilities}

Consistent recommendations are for dietetic intervention to be part of a multidisciplinary team intervention, and not an intervention to be delivered in isolation $[2,41]$.

Clinicians in eating disorder practice are also advised to have clinical supervision as a form of formal learning and reflective practice [18]. Although clinical supervision is not historically utilised in the dietetics profession [42], dietitians do highly value learning from mentors [14]. As seen in New Zealand [43], dietitians would likely benefit from more formal clinical supervision, with the aim of encouraging safe and competent practice [42]. More specifically, dietitians working in the mental health and eating disorders fields believe that supervision is required to help dietitians deal with challenging behaviours and relationships [42, 44]. The British Dietetic Association has introduced professional supervision to the dietetic profession, defining it as a "process of professional support and learning undertaken through a range of activities, which enables individuals to develop knowledge and competence, assume responsibility for their own practice and enhance service-user protection, quality and safety of care" [45]. Clinical dietetic supervision should use a model that is suited to the dietetics profession and learning style [46]. Clinical supervision has been reported by allied health professionals to be most effective when professional development was the focus of the supervision, the supervisor possessed the skills and attributes required to facilitate a constructive supervisory relationship and the workplace provided an environment that facilitated this relationship and professional development [46]. Furthermore, since dietetics training often does not have a strong counselling focus, it may be important for the supervisee and supervisor to undergo formal training to ensure competency of supervision skills [46].

\section{Nutrition care process}

The following has been developed in line with the Nutrition Care Process Terminology (NCPT) [47]. The purpose of NCPT is to provide an accurate and specific description of the services that nutrition and dietetics practitioners deliver. The aim is to achieve a common understanding of these services not only among nutrition and dietetics practitioners, but also outside the profession, including individuals with an eating disorder and other members of the multidisciplinary team [48]. Standardized terminology facilitates the clear description of nutrition care through the following four steps of the 
Nutrition Care Process: nutrition assessment, nutrition diagnosis, nutrition intervention, and nutrition monitoring and evaluation [49].

Nutrition assessment All dietitians are trained to undertake a nutrition assessment. However, when obtaining an assessment of an individual with an eating disorder (or suspected eating disorder), additional questions and tailoring of the assessment is required. Factors across the assessment domains relevant to both physical and mental health need to be considered. Particular attention should be given to the individual's beliefs about food, any dietary rules, dieting behaviour, food avoidance, attempts to reduce weight and weight history [2]. Additionally enquiring about and being aware of physical and psychological signs and symptoms of starvation such as preoccupation with food [50], hypothermia [50], bradycardia [51], postural hypotension [51], GI dysfunction [34], appetite disturbance [52], social isolation [50], depression [53] and hypoglycaemia [54] is useful. Dietitians specialising in eating disorder treatment should also ask about the frequency and triggers for eating disorder behaviours such as binge eating, and compensatory behaviours such as vomiting, laxative use, and excessive exercise [2]. It is important to be aware that eating disorders can occur in individuals of any age, gender or body size, cultural background and demographic [55].

Nutrition diagnoses Dietitians working in the eating disorders field identify and manage specific nutrition problems and diagnoses resulting from the psychological and physical complications associated with an eating disorder (e.g. malnutrition) [2]. A nutrition diagnosis is different from a medical/psychiatric diagnosis, and while identifying eating disorder signs and symptoms is expected, providing a medical or psychiatric diagnosis is not within the dietitian's scope of practice.

Nutrition intervention The role of the dietitian is to identify, plan and implement appropriate nutrition interventions with the purpose of modifying nutrition-related health status, behaviours, knowledge and attitudes to achieve physical, psychological and nutritional recovery, as well as support behaviours and attitudes to best sustain an individual's wellbeing [2]. This places the dietitian in an ideal role to contribute towards eating disorder recovery. A standardised nutrition intervention should involve prioritising the goals and expected outcomes, the development of an appropriate nutrition plan as required, establishment of interdisciplinary connections and the implementation, documentation and revision of the plan as required [2]. Wherever possible, the nutrition intervention should be collaboratively undertaken with the client.
Nutrition intervention planning. Eating disorders present both psychiatric and medical risk which needs to be considered in planning nutrition interventions. Given the dietary rigidity present in eating disorders, dietitians need to consider how their interventions either support or discourage eating flexibility and normalised eating patterns. In contrast to broad public healthy eating guidelines, nutrition interventions should be designed to minimise exclusion of any foods including those considered nutrient poor. Individuals with an eating disorder generally experience high levels of anxiety about eating, which may affect the individual's readiness for change and tolerance of uncertainty. Dietitians need to tailor their treatments to support individuals towards recovery while providing safe and ethical nutrition interventions $[7,56,57]$.

\section{Nutrition intervention implementation}

1. Food and nutrient delivery: Food and nutrient delivery are tailored to the individual's nutrition needs, but the individual's stage of recovery will help to inform the treatment plan. The treatment plan considers evidence about specific foods and nutrients for weight restoration, appetite regulation, lifecycle nutrition, the presence of co-occurring psychiatric and medical conditions that affect nutritional status, and stage of recovery. In an inpatient setting, dietitians may advise the multidisciplinary team on the most appropriate method of nutrient delivery such as oral feeding, nutrition supplements and/or nasogastric feeding [12, 57-59].

2. Nutrition education: Nutrition education is provided throughout treatment and across all treatment settings. This includes information regarding energy and nutrient needs [60], the impact of food and nutrients on physical and psychological wellbeing, effects of energy or nutritional deficiency, appetite cues and the relationship between dietary intake and exercise. Other topics that may be relevant for nutrition education include dietary iron and calcium requirements, family eating patterns, eating socially, shopping and cooking skills, metabolism and gastrointestinal function [59]. Education should be directed towards the person who is most responsible for making eating decisions and this may be the individual, family, or carer and is dependent on the psychological treatment model [56]. Education serves to support the individual and/ or family in considering the potential benefits of incorporating sustainable change in eating patterns and behaviours to promote the recovery process. The specific timing and topics of education should be person-centred, varying according to the stage of change. 
3. Nutrition counselling: Nutrition counselling is provided to individuals and families, and complements the psychological model used in therapy. Nutrition and dietetic counselling practices have been identified and include but are not limited to monitoring eating behaviour, beliefs and attitudes about food and health, rationale for food choice, factors affecting eating behaviour and nutritional status, factors affecting access to food, motivation and stages of change and addressing ambivalence and barriers to behaviour change [61]. There should be an awareness of the evidence-based psychological models used in eating disorder treatment (as outlined by Hilbert et al. [62]). Understanding and complementing a psychological model with dietetic care as part of the multidisciplinary team is different from the dietitian implementing the model, and while understanding the principles of models of care for eating disorders is expected, implementing a psychological treatment model is not considered to be within the dietitian's scope of practice without significant additional mental health training and supervision.

Coordination of nutrition care. Due to the high level of multi- and interdisciplinary care that occurs in eating disorder treatment, coordinating nutrition care between professionals is particularly important. Eating disorder treatment necessarily includes traditionally dietetic tasks, such as weighing individuals and discussing food and eating. Defining clear roles, boundaries and communication pathways between professionals involved in care can help streamline effective care, minimise professional burnout and enhance client outcomes $[44,63]$.

Monitoring and evaluation Throughout treatment, ongoing nutritional monitoring is required to evaluate outcomes of treatment and particularly change in eating disorder behaviour. Due to the focus on nutritional recovery in eating disorder treatment, other members of the treatment team will also likely have a role in ongoing monitoring and evaluation. It is important that treatment outcomes are evaluated both qualitatively (e.g. change in the individual's perceived relationship with food) and quantitatively (e.g. change in nutritional intake). New and developing concerns need to be addressed with the individual and communicated to the rest of the treatment team as a lack of change in eating and eating disordered behaviour may indicate a need to review treatment.

\section{Dietetic-specific clinical training standards}

Dietetic-specific clinical training should either partially or entirely address the dietetic-specific clinical practice standards outlined above and detailed in Table 1, depending on the duration and intensity of the training course. It is expected that training programs that educate dietitians working with individuals with eating disorders should identify which of the standards they address. The dietetic-specific clinical training standards use the NCPT. Currently, dietitians broadly agree that university training does not adequately prepare graduates for providing eating disorder nutrition care and additional training after graduation is often sought $[10$, 14, 15]. Thus, after basic university dietetic training, training to achieve competency in these practice standards may occur via multiple pathways, including formal (e.g. postgraduate coursework, workshops, conferences) and informal (e.g. reading, intuitive learning through experience) learning opportunities [14]. Organisations and individuals providing training in the dietetic management of eating disorders should be suitably qualified, recognised for their expertise in dietetic eating disorder treatment and have significant experience implementing eating disorder nutrition care.

\section{Implementation and future directions}

This paper provides a comprehensive outline of the skills and knowledge that a dietitian requires to provide effective and safe eating disorder treatment. It also describes the training and supervision required by dietitians, with the practice standards forming the basis of the essential elements of training. With the growing recognition that basic dietetic training at university does not adequately prepare dietitians for working with individuals with eating disorders $[10,14,15]$, these practice and training standards may guide the enhancement of undergraduate coursework on the skills and knowledge necessary for such work and the development of postgraduate learning pathways.

The role and scope of practice of the dietitian presented also clarifies the skills and knowledge that the dietitian contributes to the multidisciplinary treatment team. It increases the understanding of how dietetic intervention assists individuals to achieve recovery from an eating disorder and ensures accurate nutrition advice is delivered [11]. Furthermore, it builds an appreciation of the specialised perspective that each member of the multidisciplinary team brings to a coordinated treatment plan, creating a continuum of cohesive care for the individual with an eating disorder.

Documentation of the current practice and training standards meet a long-standing need of the dietetic community who deliver eating disorder treatment, detailing the minimum skills and knowledge in which a dietitian should be trained. However, a process for determining competence to provide dietetic treatment in the eating disorder field has not yet been characterised. The future incorporation of these practice standards into training 
processes and programs is an essential first-step to ensure future dietitians can be adequately educated and supported to work in the eating disorder field.

\section{Acknowledgements}

For supporting and providing feedback on the development of the practice standards, the authors would like to thank the ANZAED Executive Committee members: Kim Hurst (President), Sian McLean (President Elect), Mandy Goldstein (Secretary), Shane Jeffrey (Treasurer), Gabriella Heruc (Past President), Linsey Atkins, Kiera Buchanan, Shannon Calvert, Anthea Fursland, Deb Mitchison, Randall Long, Marion Roberts, Jessica Ryan and Fiona Sutherland. We also appreciate the guidance and advice received from the ANZAED Past Presidents Committee: Phillipa Hay, Sloane Madden, Susan Paxton, Beth Shelton, Chris Thornton. We would also like to acknowledge the additional expert advisors, Chris Basten and Claire Toohey, as well as all individuals who provided feedback during the face-to-face and public online consultation process. We are grateful for the input provided by the Dietitian's Association of Australia, Occupational Therapy Australia, the Australian Psychological Society, the Royal Australia and New Zealand College of Psychiatrists, Eating Disorders Queensland (EDQ), Eating Disorders Families Australia (EDFA), the Butterfly Foundation and the ANZAED Consumer and Career Committee. We also offer our sincere thanks to the National Eating Disorders Collaboration Steering Committee for their comments and contributions.

\section{Authors' contributions}

$\mathrm{GH}$ and $\mathrm{KH}$ co-chaired the working groups and led the development of the practice standards; GH, SH and GS wrote the manuscript; all authors contributed to the initial practice standards draft and read and approved the final manuscript.

\section{Funding}

ANZAED provided financial support for the meetings, public consultations, writing and publication costs associated with the development of these practice standards.

\section{Availability of data and materials}

Not applicable.

\section{Ethics approval and consent to participate}

Not applicable.

\section{Consent for publication}

Not applicable.

\section{Competing interests}

Not applicable.

\begin{abstract}
Author details
${ }^{1}$ Executive Committee, Australia \& New Zealand Academy for Eating Disorders, Sydney, Australia. ${ }^{2}$ School of Medicine, Western Sydney University, Campbelltown, Australia. ${ }^{3}$ Eating Disorder Service, Northern Sydney Local Health District, Sydney, Australia. ${ }^{4}$ Nutrition and Dietetics, St Vincent's Hospital, Darlinghurst, Australia. ${ }^{5}$ The Boden Collaboration of Obesity, Nutrition, Exercise and Eating Disorders, The University of Sydney, Sydney, Australia. ${ }^{6}$ School of Sport, Exercise and Nutrition, College of Health, Massey University, Auckland, New Zealand. ${ }^{7} T$ The Swan Centre, Perth, Australia. ${ }^{8}$ Centre for Psychotherapy, Hunter New England Local Health District, Newcastle, Australia. ${ }^{9}$ The Mindful Dietitian, Melbourne, Australia. ${ }^{10}$ River Oak Health, Brisbane, Australia. ${ }^{11}$ Royal Brisbane and Women's Hospital, Brisbane, Australia. ${ }^{12}$ Victorian Centre of Excellence in Eating Disorders, Parkville, Australia. ${ }^{13}$ Eating Disorder Service, Robina Private Hospital, Robina, Australia. ${ }^{14}$ Griffith University, Gold Coast, Australia.
\end{abstract}

Received: 5 August 2020 Accepted: 2 October 2020

Published online: 15 December 2020

\section{References}

1. Hay P, Chinn D, Forbes D, Madden S, Newton R, Sugenor L, et al. Royal Australian and new Zealand College of Psychiatrists clinical practice guidelines for the treatment of eating disorders. Aust N Z J Psychiatry. 2014; 48(11):977-1008
2. Ozier AD, Henry BW. Position of the American dietetic association: nutrition intervention in the treatment of eating disorders. J Am Diet Assoc. 2011; 111(8):1236-41.

3. National Institute for Health and Care Excellence. Eating Disorders: recognition and treatment [NG69]. National Institute for Health and Care Excellence; 2017.

4. Arcelus J, Mitchell AJ, Wales J, Nielsen S. Mortality rates in patients with anorexia nervosa and other eating disorders: a meta-analysis of 36 studies. Arch Gen Psychiatry. 2011;68(7):724-31.

5. Lang K, Glennon D, Mountford V, McClelland J, Koskina A, Brown A, et al. Early intervention for eating disorders. In: Wade T, editor. Encyclopedia of feeding and eating disorders. Singapore: Springer Singapore; 2016. p. 1-6.

6. Cardenas D. What is clinical nutrition? Understanding the epistemological foundations of a new discipline. Clin Nutr ESPEN. 2016;11:e63-e6.

7. Hart S, Russell J, Abraham S. Nutrition and dietetic practice in eating disorder management. J Hum Nutr Diet. 2011;24(2):144-53.

8. McMaster C, Wade T, Franklin J, Hart S. Development of consensus-based guidelines for outpatient dietetic treatment of eating disorders: a Delphi study. Int J Eat Disord. 2020; in press.

9. Mittnacht AM, Bulik CM. Best nutrition counseling practices for the treatment of anorexia nervosa: a Delphi study. Int J Eat Disord. 2015;48(1):111-22.

10. Trammell EL, Reed D, Boylan M. Education and practice gaps of registered dietitian nutritionists working with clients with eating disorders. Top Clin Nutr. 2016;31(1):73-85

11. McMaster CM, Wade T, Franklin J, Hart S. A review of treatment manuals for adults with an eating disorder: nutrition content and consistency with current dietetic evidence. Eat Weight Disord. 2020. https://doi.org/10.1007/ s40519-020-00850-6.

12. Reiter CS, Graves L. Nutrition therapy for eating disorders. Nutr Clin Pract. 2010;25(2):122-36.

13. Setnick J. Academy of nutrition and dietetics pocket guide to eating disorders. 2nd ed. Cleveland: American Dietetic Association; 2016.

14. Cairns J, Milne RL. Eating disorder nutrition counseling: strategies and education needs of english-speaking dietitians in Canada. J Am Diet Assoc. 2006;106(7):1087-94.

15. Denman E, Parker E, Ashley M, Harris D, Halaki M, Flood V, et al. Understanding training needs in eating disorders of graduating and new graduate dietitians: an online survey. Nutr Diet. 2020; (in submission).

16. Cant R, Aroni R. From competent to proficient; nutrition education and counselling competency dilemmas experienced by Australian clinical dietitians in education of individuals. Nutr Diet. 2008;65(1):84-9.

17. Lu AH, Dollahite J. Assessment of dietitians' nutrition counselling selfefficacy and its positive relationship with reported skill usage. J Hum Nutr Diet. 2010;23(2):144-53.

18. Heruc G, Hurst K, Casey A, Fleming K, Freeman J, Fursland A, et al. ANZAED eating disorder treatment principles and general clinical practice and training standards. J Eat Disord. 2020;8:63. https://doi.org/10.1186/s40337020-00341-0.

19. Hurst K, Heruc G, Thornton C, Freeman J, Fursland A, Knight R, et al. ANZAED practice and training standards for mental health professionals providing eating disorder treatment. J Eat Disord. 2020;8:58. https://doi.org/ 10.1186/s403337-020-00333-0.

20. Morgan JF, Reid F, Lacey JH. The SCOFF questionnaire. West J Med. 2000; 172(3):164.

21. Herman BK, Deal LS, DiBenedetti DB, Nelson L, Fehnel SE, Brown TM. Development of the 7-item binge-eating disorder screener (BEDS-7). Prim Care Companion CNS Disord. 2016;18(2). https://doi.org/10.4088/PCC.15m01896.

22. Fursland A, Watson HJ. Eating disorders: a hidden phenomenon in outpatient mental health? Int J Eat Disord. 2014:47(4):422-5.

23. Hautala L, Junnila J, Alin J, Grönroos M, Maunula A-M, Karukivi M, et al. Uncovering hidden eating disorders using the SCOFF questionnaire: crosssectional survey of adolescents and comparison with nurse assessments. Int J Nurs Stud. 2009:46(11):1439-47.

24. McCuen-Wurst C, Ruggieri M, Allison KC. Disordered eating and obesity: associations between binge-eating disorder, night-eating syndrome, and weight-related comorbidities. Ann N Y Acad Sci. 2018;1411(1):96-105.

25. Stice E, Gau JM, Rohde P, Shaw H. Risk factors that predict future onset of each DSM-5 eating disorder: predictive specificity in high-risk adolescent females. J Abnorm Psychol. 2017:126(1):38-51. 
26. Buchholz LJ, King PR, Wray LO. Identification and management of eating disorders in integrated primary care: recommendations for psychologists in integrated care settings. J Clin Psychol Med Settings. 2017:24(2):163-77.

27. Neumark-Sztainer DR, Wall MM, Haines JI, Story MT, Sherwood NE, van den Berg PA. Shared risk and protective factors for overweight and disordered eating in adolescents. Am J Prev Med. 2007;33(5):359-69.e3.

28. Patton GC, Selzer R, Coffey C, Carlin JB, Wolfe R. Onset of adolescent eating disorders: population based cohort study over 3 years. BMJ. 1999;318(7186): 765-8.

29. Clappison E, Hadjivassiliou M, Zis P. Psychiatric manifestations of coeliac disease, a systematic review and meta-analysis. Nutrients. 2020;12(1):142.

30. De Paoli T, Rogers PJ. Disordered eating and insulin restriction in type 1 diabetes: a systematic review and testable model. Eat Disord. 2018;26(4): 343-60.

31. Hedman A, Breithaupt L, Hübel C, Thornton LM, Tillander A, Norring C, et al. Bidirectional relationship between eating disorders and autoimmune diseases. J Child Psych Psych. 2019;60(7):803-12.

32. Mari A, Hosadurg D, Martin L, Zarate-Lopez N, Passananti V, Emmanuel A. Adherence with a low-FODMAP diet in irritable bowel syndrome. Eur J Gastroenterol Hepatol. 2019;31(2):178-82.

33. Smith KE, Orcutt M, Steffen KJ, Crosby RD, Cao L, Garcia L, et al. Loss of control eating and binge eating in the 7 years following bariatric surgery. Obes Surg. 2019;29(6):1773-80.

34. Riedlinger C, Schmidt G, Weiland A, Stengel A, Giel KE, Zipfel S, et al. Which symptoms, complaints and complications of the gastrointestinal tract occur in patients with eating disorders? A systematic review and quantitative analysis. Front Psychiatr. 2020;11:195.

35. Dooley-Hash S, Lipson SK, Walton MA, Cunningham RM. Increased emergency department use by adolescents and young adults with eating disorders. Int J Eat Disord. 2013;46(4):308-15.

36. Talbot BEM, Lawman SHA. Eating disorders should be considered in the differential diagnosis of patients presenting with acute kidney injury and electrolyte derangement. Case Rep. 2014;2014:bcr2013203218.

37. Schaumberg K, Anderson D. Dietary restraint and weight loss as risk factors for eating pathology. Eat Behav. 2016;23:97-103.

38. Aparicio-Llopis E, Canals J, Arija V. Dietary intake according to the course of symptoms of eating disorders in a school-based follow-up study of adolescents. Eur Eat Disord Rev. 2014;22(6):412-22.

39. Aspen $V$, Weisman $H$, Vannucci $A$, Nafiz N, Gredysa D, Kass AE, et al. Psychiatric co-morbidity in women presenting across the continuum of disordered eating. Eat Behav. 2014;15(4):686-93.

40. Stoyel H, Slee A, Meyer C, Serpell L. Systematic review of risk factors for eating psychopathology in athletes: a critique of an etiological model. Eur Eat Disord Rev. 2020;28(1):3-25.

41. Thomas D. The dietitian's role in the treatment of eating disorders. Nutr Bull. 2000;25(1):55-60.

42. Kirk SFL, Eaton J, Auty L. Dietitians and supervision: should we be doing more? J Hum Nutr Diet. 2000;13(5):317-22.

43. Paulin V. Professional supervision in dietetics: a focus group study investigating New Zealand dietitians' understanding and experience of professional supervision and their perception of its value in dietetic practice. Nutr Diet. 2010;67(2):106-11.

44. Saloff-Coste CJ, Hamburg P, Herzog DB. Nutrition and psychotherapy: collaborative treatment of patients with eating disorders. Bull Menn Clin 1993;57(4):504.

45. British Dietetic Association. BDA Practice supervision. 2020.

46. Snowdon DA, Sargent M, Williams CM, Maloney S, Caspers K, Taylor NF. Effective clinical supervision of allied health professionals: a mixed methods study. BMC Health Serv Res. 2020;20:2.

47. Academy of Nutrition and Dietetics. Nutrition Terminology reference manual (eNCPT): Dietetics language for nutrition care. 2019.

48. Swan WI, Pertel DG, Hotson B, Lloyd L, Orrevall Y, Trostler N, et al. Nutrition care process (NCP) update part 2: developing and using the NCP terminology to demonstrate efficacy of nutrition care and related outcomes. J Acad Nutr Diet. 2019;119(5):840-55.

49. Thompson KL, Davidson P, Swan Wl, Hand RK, Rising C, Dunn AV, et al. Nutrition care process chains: the missing link between research and evidence-based practice. J Acad Nutr Diet. 2015;115(9):1491-8.
50. Dalle Grave R, Pasqualoni E, Marchesini G. Symptoms of starvation in eating disorder patients. In Eds. Preedy, V.R. Watson, R.R Martin, C.R. Handbook of behavior, food and nutrition. New York: Springer; 2011. p. 2259-69.

51. Casiero D, Frishman WH. Cardiovascular complications of eating disorders. Cardiol Rev. 2006;14(5):227-31.

52. Heruc GA, Little TJ, Kohn M, Madden S, Clarke S, Horowitz M, et al. Appetite perceptions, gastrointestinal symptoms, ghrelin, peptide $Y Y$ and state anxiety are disturbed in adolescent females with anorexia nervosa and only partially restored with short-term refeeding. Nutrients. 2018;11(1):59.

53. Godart N, Radon L, Curt F, Duclos J, Perdereau F, Lang F, et al. Mood disorders in eating disorder patients: prevalence and chronology of ONSET. J Affect Disord. 2015;185:115-22.

54. Heruc GA, Little TJ, Kohn MR, Madden S, Clarke SD, Horowitz M, et al. Effects of starvation and short-term refeeding on gastric emptying and postprandial blood glucose regulation in adolescent females with anorexia nervosa. Am J Physiol Endocrinol Metab. 2018;315(4):E565-E73.

55. Mitchison D, Hay P, Slewa-Younan S, Mond J. The changing demographic profile of eating disorder behaviors in the community. BMC Public Health. 2014;14(1):943.

56. Lian B, Forsberg SE, Fitzpatrick KK. Adolescent anorexia: guiding principles and skills for the dietetic support of family-based treatment. J Acad Nutr Diet. 2019;119(1):17-22.

57. Garber AK, Sawyer SM, Golden NH, Guarda AS, Katzman DK, Kohn MR, et al. A systematic review of approaches to refeeding in patients with anorexia nervosa. Int J Eat Disord. 2016;49(3):293-310.

58. Parker EK, Faruquie SS, Anderson G, Gomes L, Kennedy A, Wearne CM, et al. Higher caloric refeeding is safe in hospitalised adolescent patients with restrictive eating disorders. J Nutr Metab. 2016;2016:5168978.

59. Hart S, Abraham S, Luscombe G, Russell J. Eating disorder management in hospital patients: current practice among dietitians in Australia. Nutr Diet. 2008;65(1):16-22.

60. Hart S, Marnane C, McMaster C, Thomas A. Development of the "Recovery from Eating Disorders for Life" Food Guide (REAL Food Guide) - a food pyramid for adults with an eating disorder. J Eat Disord. 2018;6:6.

61. Vanherle K, Werkman AM, Baete E, Barkmeijer A, Kolm A, Gast C, et al. Proposed standard model and consistent terminology for monitoring and outcome evaluation in different dietetic care settings: Results from the EUsponsored IMPECD project. Clin Nutr. 2018;37(6, Part A):2206-16.

62. Hilbert A, Hoek HW, Schmidt R. Evidence-based clinical guidelines for eating disorders: international comparison. Curr Opin Psychiatr. 2017;30(6):423.

63. McDevitt S, Passi V. Evaluation of a pilot interprofessional education programme for eating disorder training in mental health services. Ir J Psychol Med. 2018;35(4):289-99.

\section{Publisher's Note}

Springer Nature remains neutral with regard to jurisdictional claims in published maps and institutional affiliations.

Ready to submit your research? Choose BMC and benefit from:

- fast, convenient online submission

- thorough peer review by experienced researchers in your field

- rapid publication on acceptance

- support for research data, including large and complex data types

- gold Open Access which fosters wider collaboration and increased citations

- maximum visibility for your research: over $100 \mathrm{M}$ website views per year

At BMC, research is always in progress.

Learn more biomedcentral.com/submission 